\title{
EFECTOS DE LA REALIDAD AUMENTADA EN EL TURISMO DE RUINAS HISTÓRICAS
}

\section{EFFECTS OF AUGMENTED REALITY IN THE TOURISM OF HISTORICAL RUINS}

\section{LUIS MAÑAS-VINIEGRA}

Profesor asociado

Facultad Ciencias de la Información.

Universidad Complutense de Madrid

Avda. Complutense, s/n, Madrid (España), 28040

Tlfn: + 34652368541

Email:Lmanas@ucm.es

PALABRAS CLAVES

Smart city, Realidad aumentada, Realidad virtual, Turismo, Ruinas históricas,

Interactividad.

\section{KEY WORDS}

Smart city, Augmented reality, Virtual reality, Tourism, Historical ruins, Interactivity. 


\title{
Resumen
}

Las nuevas tecnologías han proporcionado interactividad a las ciudades en su relación con el ciudadano, permitiendo al turista contextualizar su visita con información adicional. En el caso del turismo de ruinas históricas o conjuntos arqueológicos, el deterioro causado por el paso de los siglos lleva a que algunos turistas sientan cierta decepción ante el estado de conservación, como sucede actualmente en Pompeya, a pesar del plan de restauración iniciado en 2014. A pesar de la permanente reticencia a reconstruir estas ruinas históricas más allá de su restauración, la realidad virtual y la realidad aumentada permiten actualmente una reconstrucción simulada a partir de las ruinas existentes, que permanecen, con una calidad y una comodidad en los equipos de visión desconocidas hasta ahora. En este contexto, la presente investigación realiza un estudio exploratorio sobre las posibilidades tecnológicas al alcance de los conjuntos históricos para, a continuación, realizar una encuesta y dos focus groups que permitan conocer su aceptación de estas aplicaciones interactivas, incluyendo un análisis de emociones que permite concluir que la realidad aumentada es la mejor opción de las existentes actualmente.

\begin{abstract}
The new technologies have provided interactivity to the cities in their relationship with the citizen, allowing tourists to contextualize their visit with additional information. In the case of tourism of historical ruins or archaeological complexes, the natural deterioration causes a certain disappointment with the state of conservation, as it happens in Pompeii, despite the restoration plan started in 2014. Despite the reluctance to reconstruct these historical ruins beyond their restoration, virtual reality and augmented reality allow a simulated reconstruction from the existing ruins, which remain, with a quality and comfort in the equipment of vision unknown until now. In this context, this research makes an exploratory study about the technological possibilities available to historical ruins. Then, a survey and two focus groups are created to know the acceptance of these interactive applications, including an analysis of emotions that concludes that augmented reality is the best choice of the current ones.
\end{abstract}




\section{Introducción}

El 16\% del PIB español (INE, 2016) procede del turismo y el elevado patrimonio histórico con el que cuenta el país, en el que se encuentran 45 bienes inscritos en la Lista de Patrimonio Mundial, hace previsible que cada vez repercuta más en su crecimiento (UNESCO, 2005). Uno de los bienes declarados Patrimonio Mundial es el conjunto arqueológico de Mérida, en España, que ostenta esta distinción desde 1993 por la conservación de su colonia romana, denominada Emerita Augusta (MECD, s.f.), siendo allí donde se ha realizado esta investigación.

Algunas investigaciones ya han puesto de manifiesto el carácter didáctico y la difusión que la realidad aumentada puede aportar al patrimonio cultural (Ruiz-Torres, 2011; Acién, Barrios, Ruiz, y Fernández, 2010), así como su carácter transformador, que va más allá de la mera información que amplían (Bustamante y Prieto, 2015). Hay que considerar que aplicaciones como Google Street View (Rodríguez-Silgo, 2015) o Youtube permiten recorrer con la visión de cámaras $360^{\circ}$ desde un dispositivo o con gafas de realidad virtual Google Cardboard lugares destacados del patrimonio histórico, como las ruinas de Pompeya o el interior del Museo del Prado. Sin embargo, es necesario acudir a dispositivos y tecnología de realidad virtual o realidad aumentada para poder obtener información adicional sobre el cuadro que estamos visualizando o para comprobar cómo eran las ruinas en su estado original de construcción. En cualquier caso, no podemos olvidar que el estudio de la ciudad inteligente o smart city ha obviado el aprovechamiento de "la riqueza cultural española, su inigualable variedad y autenticidad" (Bonete, 2005:1).

La realidad virtual es una representación digital que produce idénticos efectos en la percepción de los objetos con respecto a la realidad física (Castañares, 2011:62) y que pretende lograr la mayor similitud posible con esa realidad. Hasta hace pocos años, el realismo en esa representación era la gran carencia de la realidad virtual (Biocca \& Levy, 1995), que además estaba limitada a la utilización de las cave automatic virtual environment o espacios en los que las imágenes se proyectaban en las paredes de un cubo, en cuyo centro se situaba el usuario con sus gafas estereoscópicas, cuyo coste de adquisición era, además, muy elevado.

Actualmente, el miedo a lo desconocido que subyace en el concepto de distopía (Cuadrado, 2011:8) se ha reducido y la aparición de nuevos equipos de menor tamaño, precio más asequible para el gran consumo y, sobre todo, la posibilidad de utilizarlos con libertad de movimiento han contribuido al auge de la realidad virtual en actividades formativas y socioculturales de diversa índole, entre las que se encuentran las experiencias inmersivas que proporcionan (Heim, 1993) en los museos.

La realidad aumentada, en cambio, implica una visión directa de la realidad que puede combinarse con una visión indirecta a través de un dispositivo, habitualmente el teléfono móvil, que permite incorporar a esa realidad elementos virtuales, creando una nueva realidad que combina la física y la aumentada (Cabero y García, 2016; Cobo y Moravec, 2011). Esa simulación debe cumplir un requisito esencial para su aplicación a las experiencias turísticas, como es el de la interacción (Vera, Ortega y Burgos, 2003), puesto que es el propio usuario quien debe tener el control de las acciones que va a visualizar a través de la realidad 
aumentada, saliendo de la experiencia no inmersiva, automatizada y despersonalizada de las audioguías que tradicionalmente ha ofrecido el sector turístico como elemento tecnológico interactivo.

La realidad aumentada añade a la realidad nuevas capas, ya sean de texto, imágenes, animaciones o modelados 3D. Estas nuevas capas son virtuales y se han popularizado a partir del uso trivial de redes sociales de imágenes como Snapchat o Instagram y por el videojuego Pokémon Go. Es el teléfono móvil o tablet el dispositivo que se encarga de crear ese entorno aumentado a partir de una app que permite al dispositivo escanear automáticamente la realidad para incorporar esas nuevas capas virtuales. La diferenciación entre ambas funcionalidades interactivas que ofrece la realidad aumentada aplicada al turismo permite establecer una doble clasificación:

- $\quad$ Orientada al patrimonio mediante la reconstrucción virtual.

- $\quad$ Orientada al guiado con información adicional del entorno (Leiva, Guevara, Rossi y Aguayo, 2014).

La función de guiado sustituye a las tradicionales audioguías en cuanto a la narración, pero, sobre todo, permite incluir información adicional, ya sea sobre el propio elemento que se visiona, su entorno o los servicios que encontramos en el lugar que registra la visualización.

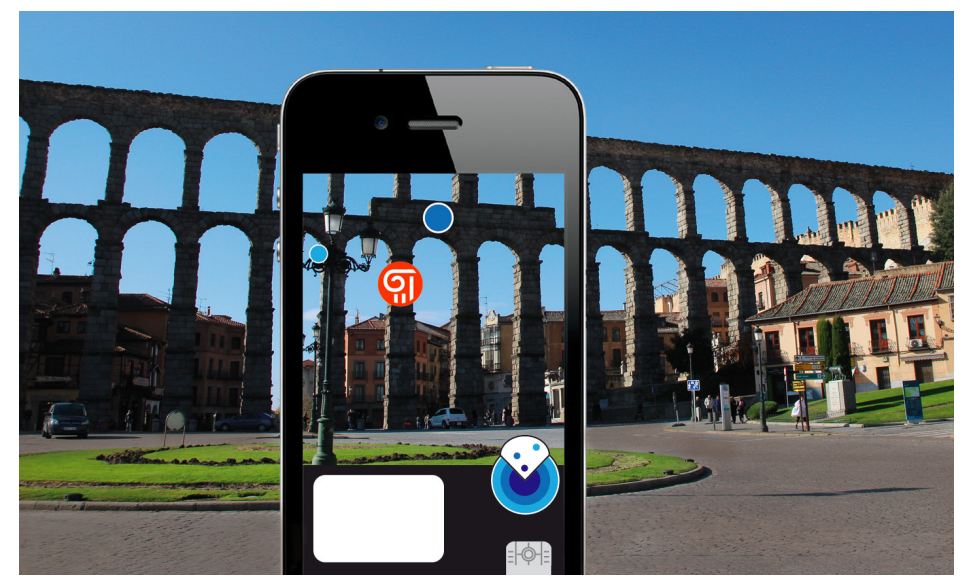

Figura 1. Realidad aumentada con información adicional en Segovia. Fuente: goo.gl/6FQwQf

La manera más básica de orientar la realidad aumentada al patrimonio consiste en mostrar una fotografía o vídeo sobre cómo era el lugar físico en el que nos encontramos en una época pasada, aunque la interactividad en este caso es mínima y la experiencia turística, insuficiente. 


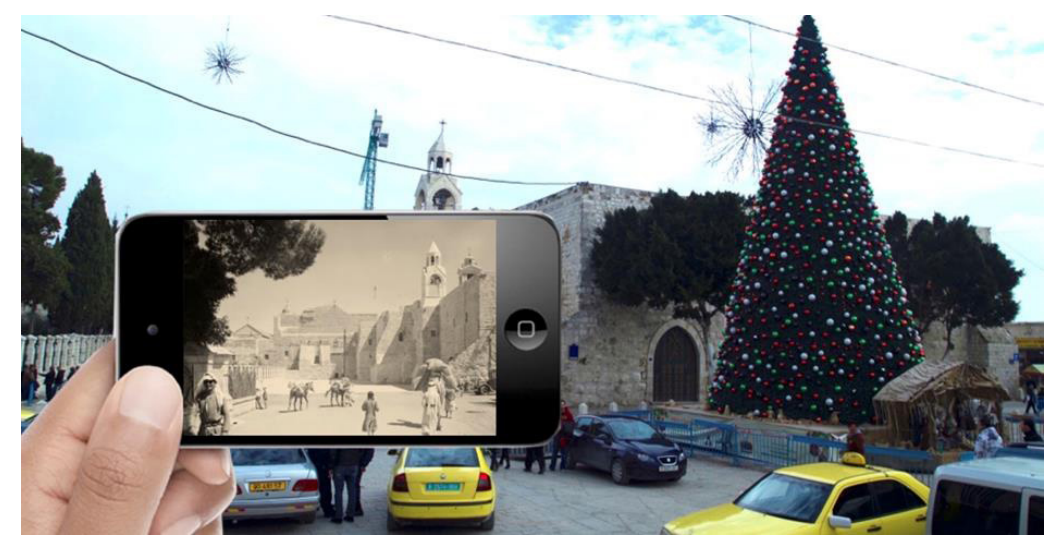

Figura 2. Realidad aumentada basada en imagen estática.

Fuente: http://www.neosentec.com/wp-content/uploads/2017/02/past.jpg

La reconstrucción virtual basada en la realidad aumentada permite incorporar un auténtico modelado $3 \mathrm{D}$ realista y un movimiento dinámico basado en la cámara $360^{\circ}$ en función del movimiento que experimenta el dispositivo.

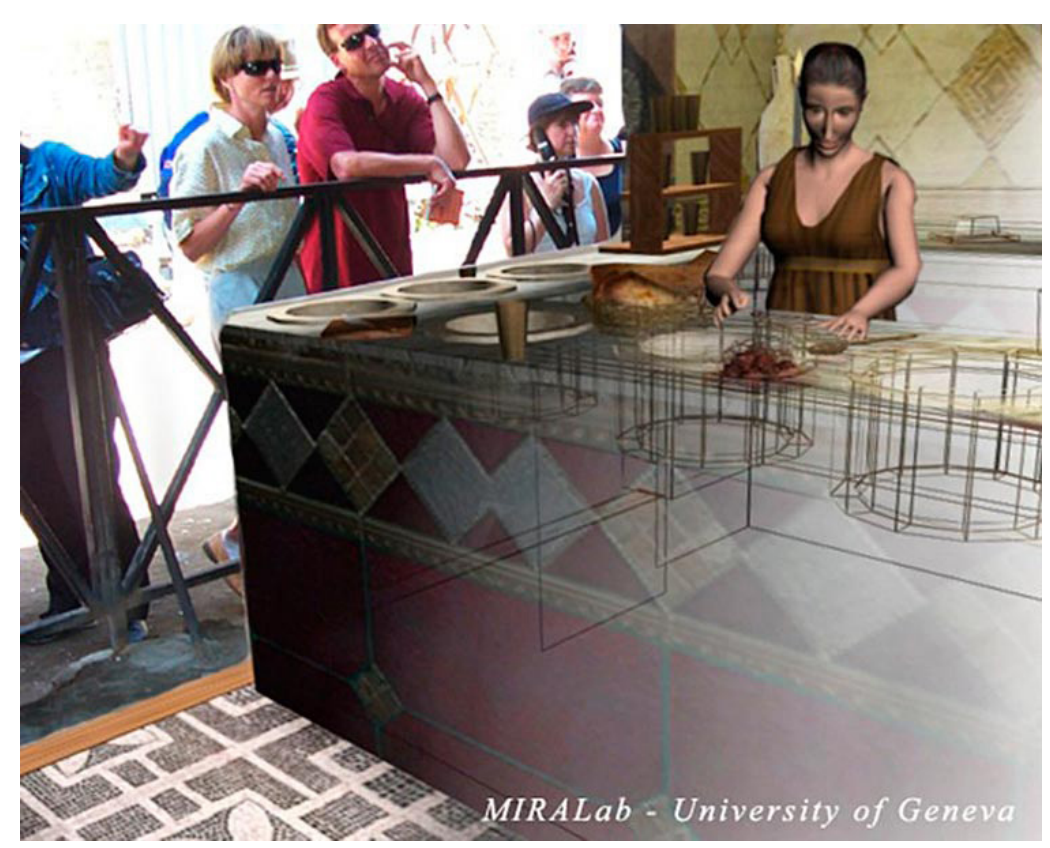

Figura 3. Reconstrucción de una taberna en Pompeya con realidad aumentada. Fuente: http://www.revistadepatrimonio.es/revistas/numero8/difusion/estudios2/fotos/popup02.html

Los efectos de la era postdigital (Cascone, 2000) aún se encuentran en pleno desarrollo, por lo que es escasa la evaluación realizada hasta el momento, siendo necesario priorizar en el caso de la realidad virtual y la realidad aumentada su capacidad para generar interés, atención y una experiencia satisfactoria en el turista de ruinas históricas.

\section{Objetivos}

Esta investigación analiza el incremento del interés turístico de las ruinas históricas a partir del soporte tecnológico de la realidad aumentada partiendo de un estudio exploratorio realizado en el conjunto 
arqueológico de Mérida (España).

Los objetivos que persigue el desarrollo empírico son los siguientes:

- Determinar la receptividad al uso de las nuevas tecnologías en la reconstrucción de ruinas históricas.

- Analizar la mejora de la experiencia de la visita turística a partir del uso de las nuevas tecnologías.

- Establecer las emociones vinculadas a la satisfacción de la visita turística.

Las hipótesis de partida son las siguientes:

- H1: Los menores de 30 años son más receptivos al uso de las nuevas tecnologías en su visita a las ruinas históricas.

- H2: Existe una preferencia de la realidad aumentada sobre la realidad virtual en la experiencia de uso.

- H3: La satisfacción experimentada tras la visita aumenta con el uso de las nuevas tecnologías.

\section{Metodología}

La presente investigación realiza un estudio en el conjunto histórico romano de Mérida para determinar la influencia del uso de la realidad aumentada en la experiencia turística del visitante de ruinas históricas. Para ello, se ha realizado un primer estudio exploratorio basado en dos focus groups compuestos por 8 personas cada uno de entre 18 y 65 años y procedencia heterogénea que hayan viajado a algún destino de ruinas históricas durante el último año para determinar la receptividad al uso de las nuevas tecnologías en su visita. Posteriormente, la metodología aplicada ha sido una encuesta a 314 sujetos de entre 18 y 30 años (57\% mujeres y $43 \%$ hombres), por ser éste el perfil de público más receptivo, realizada a la finalización de la visita turística. El trabajo de campo se ha realizado entre junio y septiembre del año 2017.

\section{Resultados y discusión}

\subsection{Resultados sobre la receptividad al uso de las nuevas tecnologías (H1)}

La primera de las cuestiones que intentó determinar el focus group de manera exploratoria fue el grado de aceptación de los dispositivos de realidad virtual o aumentada durante una visita turística a ruinas históricas. El grupo de menor edad es unánime al afirmar que "cualquier dispositivo interactivo hace más interesante la visita, porque te permite buscar información adicional de interés" (G1). Sin embargo, el grupo de mayor edad concluye que "hay que disfrutar de la visita y los dispositivos electrónicos son una distracción, además del estorbo que supone ir cargando con ellos" (G2). Este segundo grupo también concluye que contrata a un guía si van en grupo y si lo que desean es que la visita sea comentada. 
Algunos de los intervinientes en ambos grupos matizaron la importancia de la funcionalidad y la aportación que los dispositivos añadan a la visita, puesto que no es lo mismo "la típica audioguía que tiene una narración no personalizable" (G1) que "uno donde se pueda profundizar en la información que ha despertado tu curiosidad" (G2).

El focus group de personas más jóvenes puso de manifiesto el escepticismo a la hora de valorar la utilidad de dispositivos adicionales para la visita a los propios, puesto que "normalmente tienes que pagar por ellos” (G1) y “al final, cuando quiero mayor información sobre algo, saco mi móvil y lo busco en Google” (G1).

La conclusión anterior sirvió al moderador para introducir un nuevo tema de discusión en ambos focus groups, destinados a clarificar si habitualmente se acude con el teléfono móvil a la visita turística. El grupo más joven deja claro que siempre va acompañado de su teléfono móvil, hasta el punto de que "si se me ha olvidado, vuelvo a por él" (G1). El grupo de mayor edad también concluyó que lo lleva habitualmente "por lo que pueda pasar" (G2) y, en algunos casos, "también la tablet para grabar vídeos" (G2).

En efecto, solo dos personas de las encuestadas reconocieron no haber llevado su teléfono móvil a la visita, excusándose rápidamente al indicar que habían olvidado cogerlo, siendo un hecho totalmente involuntario.

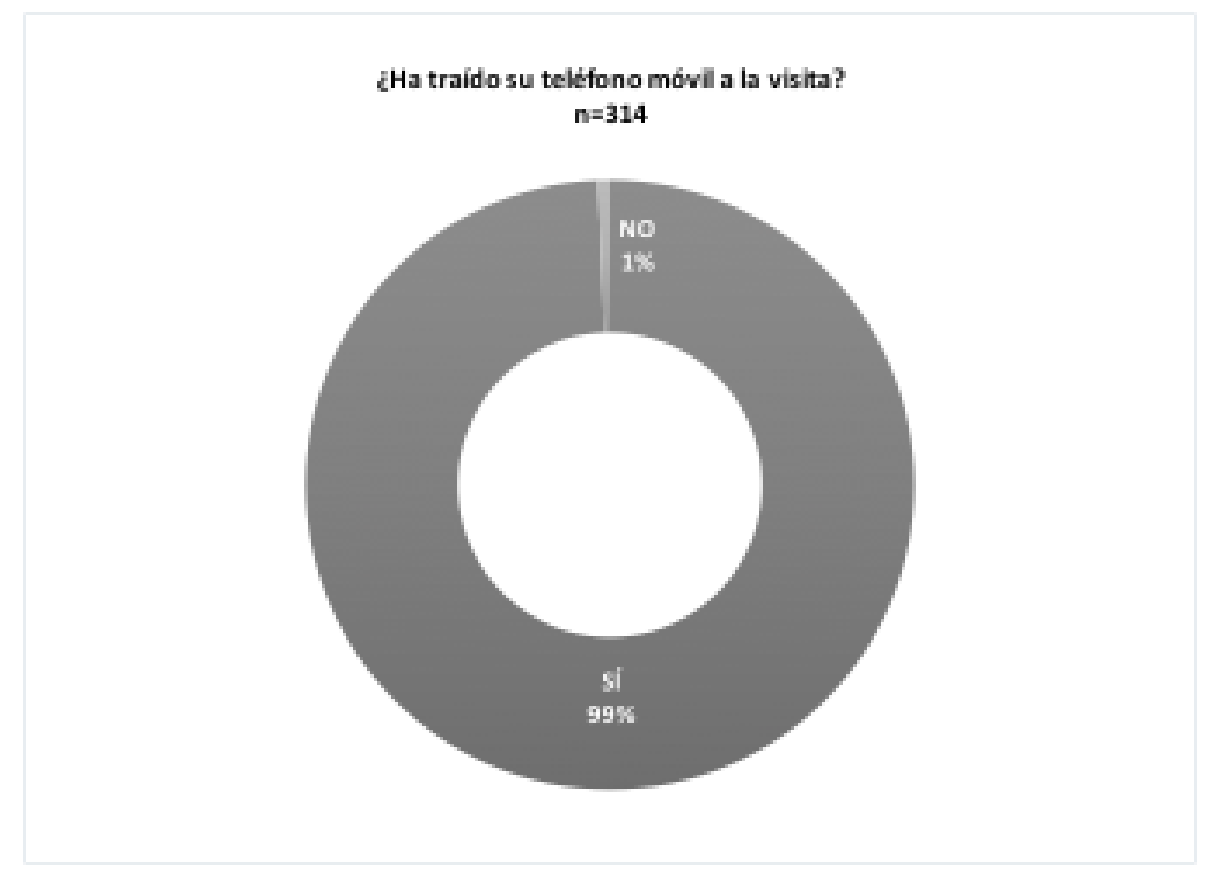

Figura 4. Equipamiento móvil durante la visita. Elaboración propia.

A continuación, se preguntó a los grupos si suelen llevar una cámara réflex a sus visitas turísticas y ambos grupos concluyeron que "es más cómodo hacer las fotos con el móvil y tienen buena calidad" (G1), aunque "a veces llevamos una cámara compacta" (G2) y "sólo cuando vamos expresamente a hacer buenas fotos llevamos la réflex" (G1). A pesar de ello, menos de un tercio de los participantes en los focus groups afirmaron tener una cámara réflex. 
Los datos de la encuesta redujeron este uso de la cámara réflex al 11\% que la habían llevado a su visita, dato que corrobora el uso del teléfono móvil como cámara de fotos más allá del uso diario, incluyendo momentos de ocio planificado en un contexto turístico.

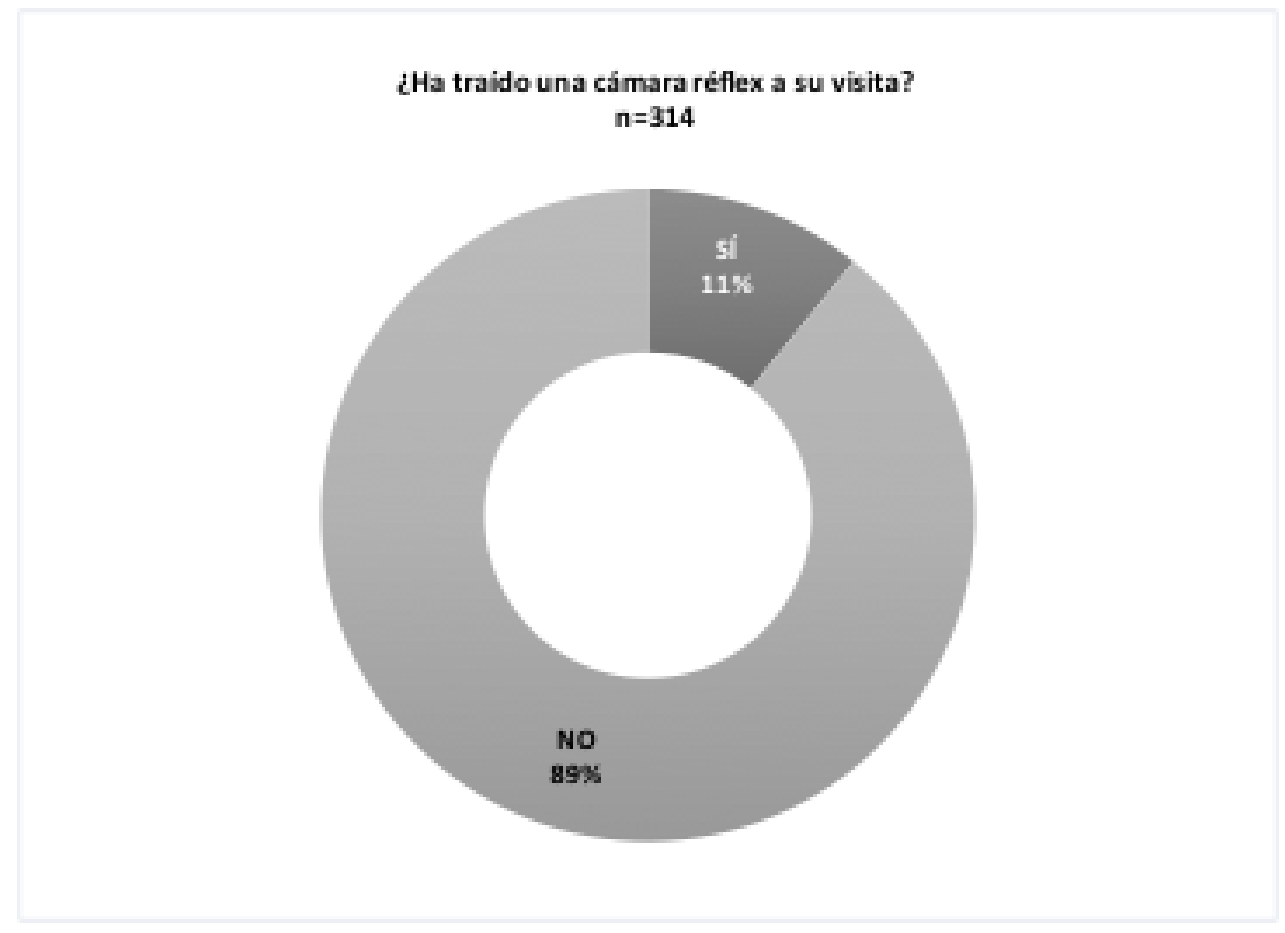

Figura 5. Uso de cámara réflex en su visita turística. Elaboración propia.

En definitiva, la predisposición al uso de los dispositivos electrónicos en la visita turística implica que es preferible utilizar los que ya acompañan a los visitantes o, en el caso de ser adicionales, aportar información adicional a la encontrada en Google y específica para los intereses de cada visitante en relación a temas concretos. El público de mayor edad, aun reconociendo que en ocasiones alquila las audioguías o compra alguna guía en papel posterior a la visita, prefiere disfrutar de la visita turística sin distracciones o, como máximo, con el acompañamiento de un guía que les oriente sobre los puntos de interés y la historia y acontecimientos asociados.

\subsection{Resultados sobre la experiencia de uso (H2)}

Las conclusiones de los focus groups en referencia a la limitada receptividad que mostraron los participantes a la hora de utilizar dispositivos adicionales a los que habitualmente les acompañan, hacen especialmente relevante la selección de dispositivos que mejoren la experiencia de la visita turística y sean realmente útiles para el interés del visitante.

Por otro lado, la escasa receptividad mostrada por el grupo de mayor edad al uso de cualquier dispositivo que le distrajera de la experiencia presencial de la visita determinó su exclusión en relación a la posibilidad de utilizar realidad virtual o realidad aumentada en sus visitas a las ruinas históricas. Consecuentemente, todas 
las conclusiones expresadas a partir de este punto se refieren a G1.

El moderador profundizó en las razones por las que los turistas más jóvenes muestran interés por el turismo de ruinas históricas. Por un lado, son personas con interés en la historia y en épocas "en las que se puede ver un estilo diferente de vida". Por otro lado, aunque previamente han visto guías y fotos en Internet y redes sociales para seleccionar el destino, "sin olvidar que luego exista un vuelo barato", en muchas ocasiones se han sentido "defraudados por el lamentable estado de conservación de muchas ruinas históricas", destacando en este aspecto la acrópolis griega y las ruinas de Pompeya por parte de los participantes. Algunos asistentes llegan a calificar algunas de estas ruinas históricas como "cuatro piedras mal conservadas" y ahí sitúan la causa de su decepción tras la visita turística.

En este punto, el moderador preguntó a los asistentes si les gustaría poder ver reconstruidas esas ruinas históricas que les defraudaron reconstruidas virtualmente, con una respuesta positiva unánime. Sin embargo, las intervenciones pronto revelaron que ya han visto reconstrucciones virtuales en Internet, pero "son infografías muy poco realistas y casi defraudan más que el mal estado de conservación de las ruinas".

El moderador explicó y mostró ejemplos de las funcionalidades que aportan tanto la realidad virtual como la aumentada a la visita turística de ruinas históricas, de modo que pudiesen ver con imágenes y de forma ilustrada cuáles son las mejoras que pueden aportar a su experiencia turística, dando así respuesta a las inquietudes mostradas por los participantes en el primer apartado de estos resultados.

La primera impresión de los participantes fue mostrar su interés por dejar de ser meros visitantes para convertirse en "el protagonista de una experiencia activa". Por tanto, las funcionalidades, por un lado, y lograr una adecuada experiencia de uso, por otro, son los principales retos a los que deben enfrentarse los dispositivos y tecnología elegidos para mejorar la satisfacción en la visita turística.

En cuanto a los dispositivos de realidad virtual, a pesar de reconocer los participantes que la experiencia inmersiva que representa "puede trasladarnos a la época que estamos visitando en las ruinas", muestran serias dudas sobre "si realmente será realista", cómodo y se podría realizar en sí la visita turística, ya que lo consideran "más para realizar la visita virtual en casa por no poder desplazarte al lugar".

Sobre el realismo, los jóvenes reconocen que se encuentran acostumbrados por la estética de los videojuegos a un realismo elevado y que, como mínimo, la realidad virtual debería superar ese grado de realismo para resultar de interés en cuanto a su utilización. Sin embargo, el realismo al que aluden no debería limitarse sólo a los edificios que se reconstruyen, sino también a las personas, ya que les gustaría "poder interactuar con el estilo de vida de la época" o "recorrer sus calles llenas de vida, no vacías".

Una de las mayores barreras que presenta la realidad virtual en relación a su uso durante la visita turística es la dificultad de movimiento que supondría "en un lugar en el que está lleno de turistas". En efecto, la realidad virtual requiere incorporar, como mínimo un visor que actúe a modo de casco y de aislamiento de la realidad para realizar la reconstrucción. Por tanto, la libertad de movimiento quedaría restringida a un espacio 
habilitado para no provocar choques con otros turistas o con las propias ruinas históricas que se pretenden reconstruir. En ese escenario, no tendría sentido realizar una recreación virtual "que no te permita ver las ruinas que precisamente has ido a visitar", ya que obligaría a hacerlo antes o después de la experiencia inmersiva de la realidad virtual.

Podemos concluir en relación al uso de la realidad virtual que su experiencia de uso no es la adecuada para el turismo de ruinas históricas y que va destinada más a un turismo sedentario virtual, con objetivos y expectativas opuestas al perfil de turista analizado. Así lo corrobora la encuesta, en la que el $88 \%$ no estaría dispuesto a realizar la visita turística con un casco de realidad virtual, frente al $6 \%$ que sí lo haría y otro $6 \%$ que no está seguro.

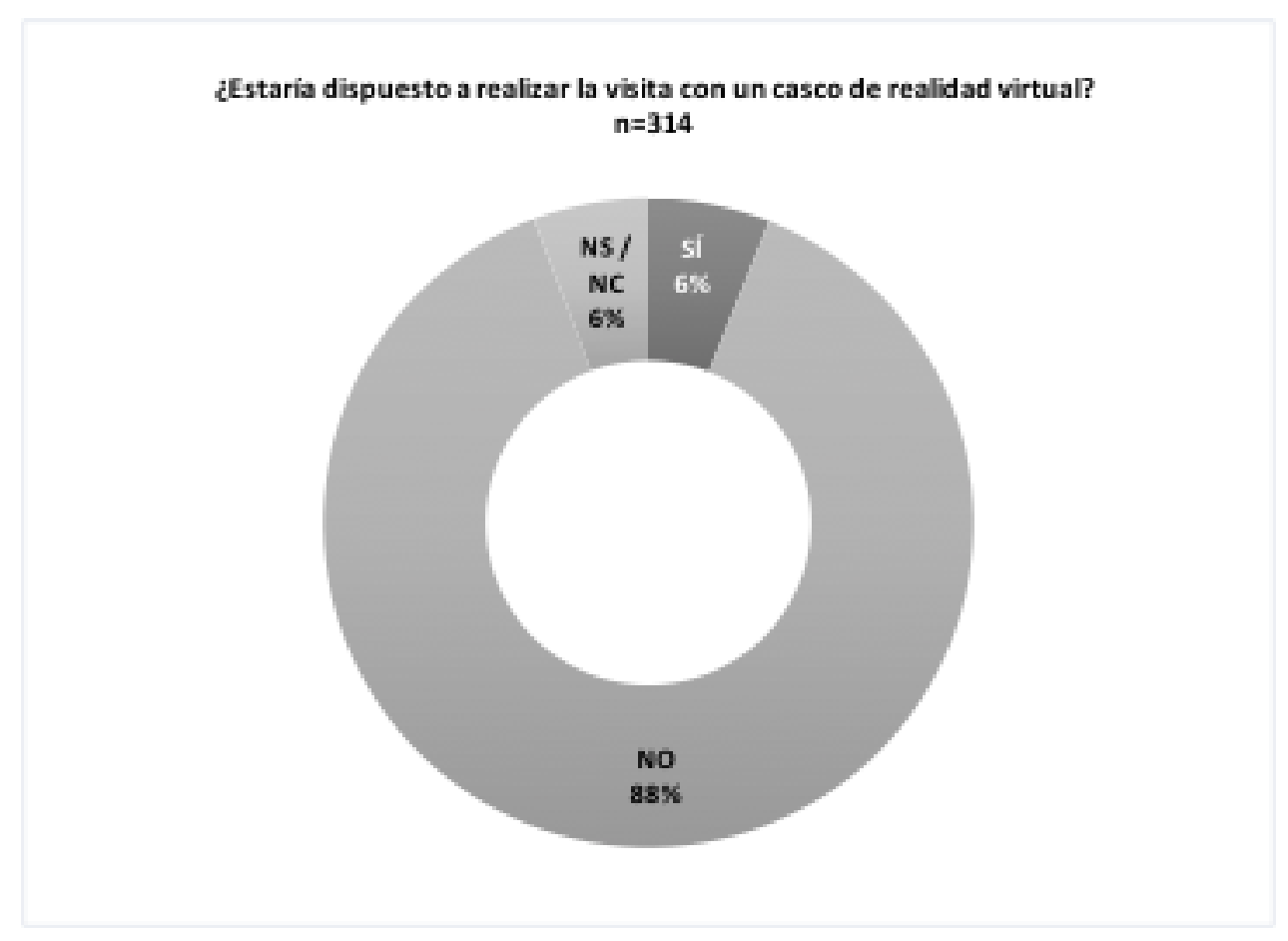

Figura 6. Preferencia para utilizar un casco de realidad virtual durante la visita. Elaboración propia

En cuanto a la experiencia de realidad aumentada, la principal fortaleza percibida en su experiencia de uso es la posibilidad de "poder combinar la visita real con la virtual". En efecto, el hecho de poder aunar información adicional que hubieran buscado en Google con una reconstrucción realizada mediante técnicas de modelado 3D lleva a la percepción de que sea "realmente útil, práctico y cómodo". Otra de las fortalezas del uso de la realidad aumentada es utilizar un dispositivo que "sí o sí vamos a llevar con nosotros", por lo que no supone ningún esfuerzo de adaptación al dispositivo, aunque facilitaría su adopción "poner wifi gratis en las ruinas para poder descargar la app necesaria para que funcione la realidad aumentada".

La encuesta corrobora también este aspecto, puesto que el $97 \%$ estaría dispuesto a utilizar la realidad aumentada siempre que el dispositivo a utilizar fuese el móvil, frente a un $3 \%$ de indecisos y ninguna negativa. 


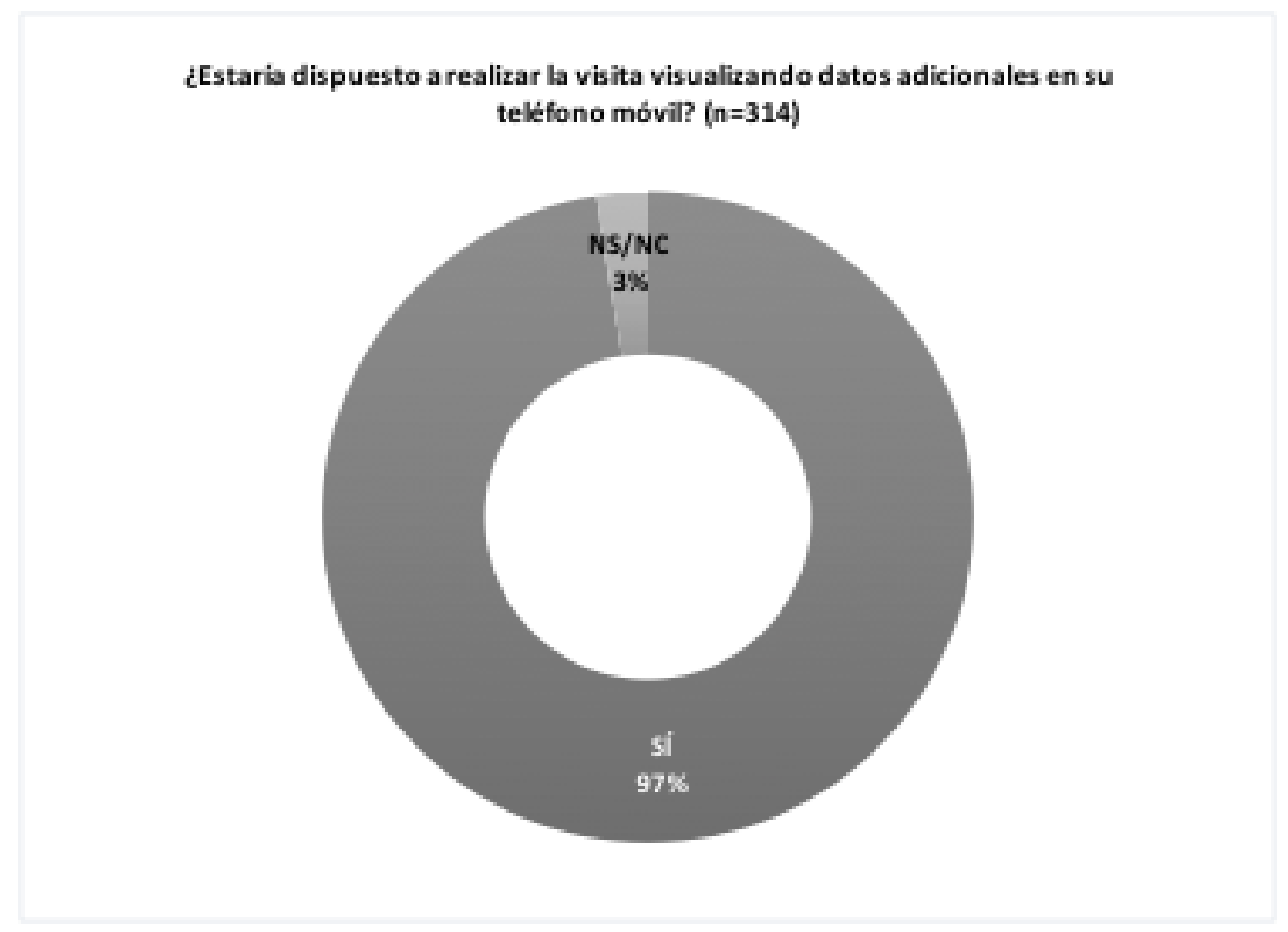

Figura 7. Preferencia para utilizar el móvil como soporte de la realidad aumentada. Elaboración propia.

Aunque califican la experiencia de "menos inmersiva" que la que puede proporcionar la realidad virtual, sí se muestran dispuestos a utilizar la realidad aumentada durante su visita turística, a pesar de que siguen encontrando "problemas de choque al ir mirando el móvil para ver las reconstrucciones". Aunque también aprecian ciertas dificultades en apreciar el detalle de la reconstrucción por el tamaño de la pantalla del dispositivo, consideran más útil el teléfono móvil que la tablet, puesto que ésta "tiene mayor tamaño y más peso, así que enseguida me cansaría de estar con el brazo levantado" y tampoco "permite guardarla en el bolsillo cuando no la utilice".

\subsection{Resultados sobre la satisfacción en la visita turística $(\mathrm{H} 3)$}

El focus group concluyó que la utilización de la realidad virtual como experiencia inmersiva no aumenta la satisfacción en la visita turística por los motivos aludidos, mientras que la realidad aumentada, al mejorar la experiencia, también mejora el conocimiento sobre las ruinas visitadas y permite disfrutar más al no tener que imaginar cómo era la ciudad en su esplendor antes de verse reducida a ruinas. Los participantes ponen de manifiesto que su aplicación mejoraría también la satisfacción de sus acompañantes, puesto que en muchas ocasiones han visitado ruinas históricas con personas que consideran que aquello no son más que "piedras sin interés". El uso de la realidad aumentada sería una forma de "tenerlo entretenido para que me deje disfrutar de la visita".

La encuesta puso de manifiesto en la respuesta múltiple que las expectativas de uso de la realidad aumentada despiertan sentimientos vinculados con el "interés", la "diversión" y la "atracción". No hubo ninguna respuesta vinculada a los sentimientos negativos de "desagrado" y "rechazo" y la "inquietud" y la "confianza" 
por la utilización de una tecnología de un modo no explorado anteriormente provoca un escaso sentimiento de "deseo". Los resultados en cuanto a sentimientos positivos son similares en ambos sexos, aunque ligeramente superiores en el caso del turista masculino.

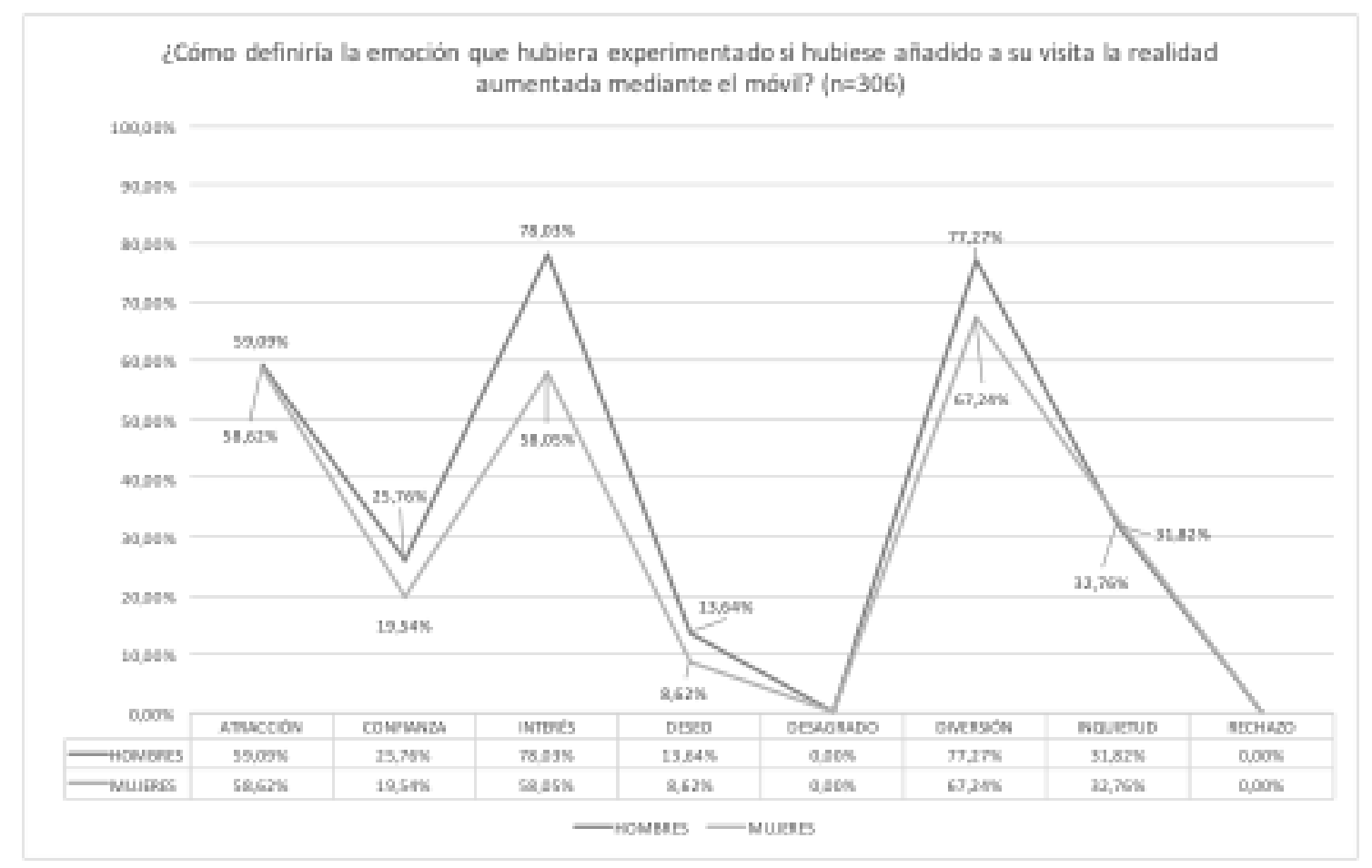

Figura 8. Análisis de emociones vinculadas al uso de la realidad aumentada en la visita turística. Elaboración propia.

\section{Conclusiones}

La investigación pone de relieve la importancia de que las ruinas históricas faciliten la interacción de sus visitantes a través de apps de realidad aumentada y permite establecer las siguientes conclusiones vinculadas a cada una de las hipótesis planteadas:

El 99\% de los menores de 30 años que visitaron las ruinas históricas de Mérida acudieron con su teléfono móvil, que habitualmente utilizan para ampliar información puntual sobre algún aspecto destacable de la visita. Sin embargo, a mayores edades se percibe que los dispositivos electrónicos son una distracción innecesaria durante la visita turística. Se confirma así $\mathrm{H} 1$.

Los visitantes menores de 30 años desean ver las ruinas históricas reconstruidas virtualmente de forma realista y participar de una experiencia activa. Sin embargo, la realidad virtual presenta demasiados inconvenientes para su aplicación durante la visita y el $88 \%$ no lo consideran como opción. En cambio, la realidad aumentada a través del teléfono móvil sería utilizada por el $97 \%$, siempre y cuando su uso sea gratuito y se proporcione wifi. Se corrobora, por tanto, $\mathrm{H} 2$. 
El uso de la realidad aumentada mejora la satisfacción experimentada en la visita turística, vinculando su utilización a emociones positivas de interés (78\%), diversión (77\%) y atracción (59\%), no existiendo emociones negativas. También queda confirmada H3.

Esta investigación abre nuevas líneas relacionadas con el desarrollo de una app de realidad aumentada para las ruinas históricas de Pompeya como prueba piloto que mejore el realismo de los intentos que se han realizado hasta ahora, centrados mayoritariamente en este conjunto arqueológico, evaluando la interacción, facilidad de uso y satisfacción de los usuarios mediante técnicas de eye-tracking y EEG.

\section{Referencias}

- $\quad$ Acién, F., Barrios, E., Ruiz, A. \& Vázquez, J.L. (2010). Mirador basado en la tecnología Realidad Aumentada para su ubicación en yacimientos arqueológicos. VAR, 1(2), 47-49. Recuperado de https:// polipapers.upv.es/index.php/var/article/view/4685/4822

- $\quad$ Biocca, F. \& Levy, M.R. (1995). Virtual reality as a communication system. En F. Biocca \& M.R. Levy (eds.), Communication in the age of virtual reality (pp. 15-31). Hillsdale: Lawrence Erlbaum Associates.

- $\quad$ Bustamante, E. \& Prieto-de-Pedro, J. (2015). Turismo, Patrimonio y NTIC. Telos, 102, 1-5. Recuperado de https://telos.fundaciontelefonica.com/url-direct/pdf-generator?tipoContenido=articuloTelos\&idContenido=2 $015110314310002 \&$ idioma=es

- $\quad$ Bonete, F. (2015). Smart cities y patrimonio cultural. Una integración necesaria para el desarrollo. Telos, 102, 1-7. Recuperado de https://telos.fundaciontelefonica.com/url-direct/pdf-generator?tipoContenido= articuloTelos\&idContenido $=2015110316500002 \&$ idioma $=$ es

- $\quad$ Cabero, J. y García, F. (2016). Realidad aumentada. Tecnología para la formación. Madrid: Síntesis.

- Cascone, K. (2000). The aesthetics of failure: "Post-Digital" tendencies in contemporary computer music. Music Journal, 24(4), 12-18. DOI: 10.1162/014892600559489

- Castañares, W. (2011). Realidad virtual: mímesis y simulación. Cuadernos de Información y Comunicación, 16, 59-81. DOI: 10.5209/rev_CIYC.2011.v16.3

- Cobo, C. \& Moravec, J.W. (2011). Aprendizaje invisible. Hacia una nueva ecología de la educación. Barcelona: Universidad de Barcelona.

- $\quad$ Cuadrado, A. (2011). Utopías y distopías de los medios digitales para la educación. Icono 14, 9(2), 5-20. DOI: 10.7195/ri14.v9i2.31

- $\quad$ Heim, M. (1993). The metaphisics of virtual reality. New York: Oxford University Press.

- INE (2016). Cuenta satélite del turismo en España. Recuperado de http://www.ine.es/dyngs/INEbase/ es/operacion.htm?c=Estadistica_C\&cid=1254736169169\&menu=ultiDatos\&idp=1254735576863

- Leiva, J.L., Guevara, A., Rossi, C. \& Aguayo, A. (2014). Realidad aumentada y sistemas de 
recomendación grupales. Una nueva perspectiva en sistemas de destinos turísticos. Estudios y Perspectivas en Turismo, 23(1), 40-59. Recuperado de http://www.scielo.org.ar/scielo.php?script=sci_arttext\&pid=S1851$17322014000100003 \&$ lng=es\&tlng=pt.

- $\operatorname{MECD}$ (s.f.). Bienes declarados Patrimonio Mundial. Conjuntos Arqueológico de Mérida. Recuperado de https://www.mecd.gob.es/cultura/areas/patrimonio/mc/patrimoniomundial/bienes-declarados/por-ano-deinscripcion/merida.html

- Rodríguez-Silgo, A. (2015). Digitalización y virtualización del patrimonio cultural. Telos, 102, 1-8. Recuperado de https://telos.fundaciontelefonica.com/url-direct/pdf-generator?tipoContenido=articuloTelos\&id Contenido $=2015110316500003 \&$ idioma $=e s$

- Ruiz-Torres, D. (2011). Realidad aumentada y Patrimonio Cultural: nuevas perspectivas para el conocimiento y la difusión del objeto cultural. Revista Electrónica de Patrimonio Histórico, 8. Recuperado de http://hdl.handle.net/10481/21792

- Vera, G., Ortega, J.A. \& Burgos, M.A. (2003). La realidad virtual y sus posibilidades didácticas. Etic@net, 2(2), 1-17. Recuperado de http://www.ugr.es/ sevimeco/revistaeticanet/Numero2/Articulos/ Realidadvirtual.pdf

- UNESCO (2005). Gestión del turismo en sitios del patrimonio mundial: Manual práctico para administradores de sitios del patrimonio mundial. París: UNESCO. Recuperado de http://unesdoc.unesco.org/ images/0012/001286/128679s.pdf 